International Conference on Renewable Energies and Power Quality (ICREPQ'11)

Las Palmas de Gran Canaria (Spain), 13th to 15th April, 2011

\title{
Performances and Acoustic Noise of Model Intelligent Wind Power Unit
}

\author{
K. Kubo ${ }^{1,3}$ and T. Kanemoto ${ }^{2}$ \\ ${ }^{1}$ Graduate School of Engineering, Kyushu Institute of Technology \\ ${ }^{3}$ Research Fellow of the Japan Society for the Promotion of Science \\ 1-1 Sensui, Tobata, Kitakyushu, 804-8550 (Japan) \\ Phone/Fax number: +81-93-884-3427, E-mail: h584104k@tobata.isc.kyutech.ac.jp \\ ${ }^{2}$ Faculty of Engineering, Kyushu Institute of Technology \\ 1-1 Sensui, Tobata, Kitakyushu, 804-8550 (Japan) \\ Phone/Fax number: +81-93-884-3418, E-mail: kanemoto@mech.kyutech.ac.jp
}

\begin{abstract}
The authors invented the superior wind power unit which is composed of the tandem wind rotors and the double rotational armature type generator without the traditional stator. The large-sized front wind rotor and the small-sized rear wind rotor drive the inner and the outer rotational armatures respectively, as for the upwind type. The unique rotational conditions of the tandem wind rotors and the fundamental performances were presented at the previous papers. Continuously, this paper discusses experimentally the effect of the blade profiles of tandem wind rotors on the performances and investigated the acoustic noise emitted from tandem wind rotors. The output of the tandem wind rotors with the desirable profiles is higher than the output of the traditional single wind rotor. The acoustic noise is induced mainly from the flow interaction between the front and the rear wind rotors, and is dominant at the blade passing frequency.
\end{abstract}

\section{Key words}

Wind Turbine, Wind Energy, Tandem Wind Rotors, Counter-Rotation, Performance, Acoustic Noise

\section{Introduction}

Wind is clean, renewable and homegrown energy resource for the electrical power generation, and has been utilized effectively to cope with the warming global environment. The traditional wind turbines with the large sized wind rotor generate the high output at the moderate wind velocity, but do not operate at the weak wind, in general. The small-sized wind rotors are suitable for the weak wind, but the output is small. That is, the size of the wind rotor must be correctly/appropriately selected in conformity with the wind circumstances. Moreover, the blade of the wind rotor must be equipped with the brakes and/or pitch control mechanisms, in general, not only to suppress the abnormal rotation and the generated over load at the strong wind but also to keep good quality of the electric power supply. To overcome these weak points of the traditional wind turbines, the authors invented the superior wind power unit ${ }^{(1)}$, as shown in Fig. 1. This unit is composed of the large-sized front wind rotor, the small-sized rear wind rotor and the peculiar generator with the inner and the outer rotational armatures without the traditional stator. As for the upwind type, the front and the rear wind rotors drive the inner and the outer rotational armatures, respectively. The rotational speeds and the directions of both wind rotors/armatures are free, and automatically adjusted pretty well in response to the wind circumstances while the rotational torques between both wind rotors/armatures are counter balanced. This unit is named "Intelligent Wind Power Unit" by the authors. The concepts of the tandem wind rotors have been proposed before. For example, Professor I. Ushiyama could increase the output using the model tandem wind rotors ${ }^{(2)}$. Kowintec Co. Ltd. has succeeded only to increase the output of the prototype wind turbine with the gearbox ${ }^{(3)}$. On the contrary, the unit proposed

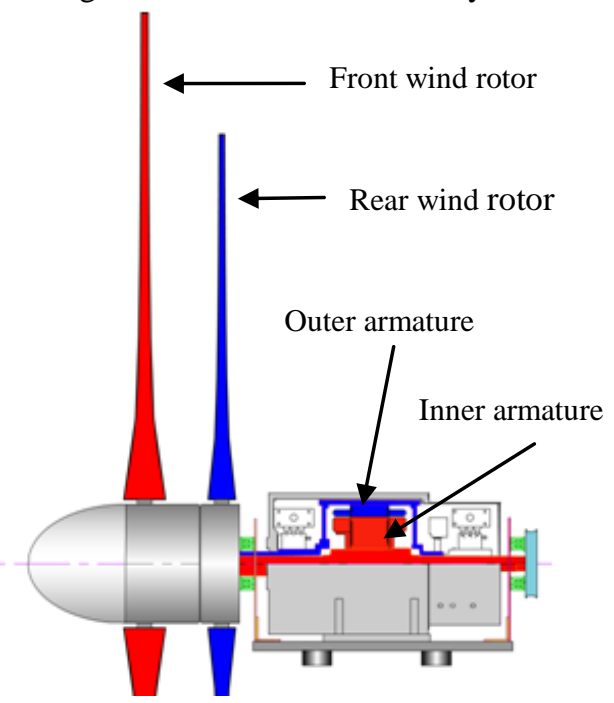

Fig.1 Upwind type Intelligent Wind Power Unit 
here quite differs from these turbines, that is, the operation of the tandem wind rotors is in cooperation with the double rotational armature type generator without the gearbox and the pitch control mechanism.

The superior operation of this type unit were verified preliminarily and the double rotational armature type generators have been prepared ${ }^{(1)(4)(5)}$. Continuously, this paper discussed the effects of the blade profiles on the performance and the acoustic noise emitted from the tandem wind rotors.

\section{Superior Operation}

The rotational directions and speeds of the tandem wind rotors /armatures are automatically adjusted in response to the wind velocity, as shown in Fig. 2, where such operations ${ }^{(1)}$ are explained briefly again for the helping the discussions of the following experimental results. Both wind rotors start to rotate at the low wind velocity, namely the cut-in wind velocity, but the rear wind rotor rotate at the counter direction of the front wind rotor. The rear wind rotor reaches the maximum rotational speed at the rated wind velocity. With more increase of the wind velocity, the rotational speed of the rear wind rotor decreases gradually, stops, and then begins to rotate at the same direction of the front wind rotor.

The following discussions are under the rated wind velocity, as the first step to optimize the wind rotor profiles playing reasonable as Fig. 2.

\section{Model Wind Rotors and Experiments}

The diameter of the front wind rotor is $d_{F}=500 \mathrm{~mm}$, and the rear is $d_{R}=420 \mathrm{~mm}$, where the diameter ratio $D_{R F}$ $\left[=d_{R} / d_{F}\right]$ is 0.84 . The axial distance between the front and the rear wind rotors is $l=40 \mathrm{~mm}$ at the twist centres. The front and the rear bade numbers are $Z_{F}=3, Z_{R}=5$. These dimensions $\left(D_{R F}, l, Z_{F}\right.$ and $\left.Z_{R}\right)$ were optimized in the previous papers ${ }^{(1)(5)}$. The blade profiles of the front and the rear wind rotors are shown in Figs. 3 and 4. Front Blade $\mathrm{G}$ has MEL002 aerofoil $^{(6)}$ and has the twist to get the desirable attack angle $\alpha=7$ degrees, as the single wind rotor (see Fig. 3). Rear Blade E has no camber and the twist (see Fig. 4). Rear Blade G also has MEL002 ${ }^{(6)}$ and has the twist to get the desirable attack angle $\alpha=11$ degrees (see Fig. 4), considering the flow conditions at the downstream of the single wind rotor (refer to Fig. 10). Hereafter, the tandem wind rotors are

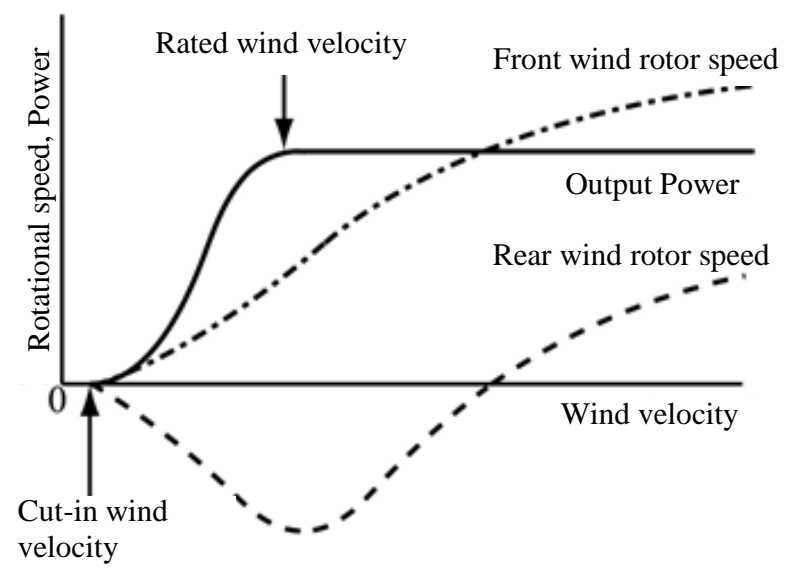

Fig.2 Operation of Intelligent Wind Power Unit called "Tandem Wind Rotor GE" which is composed of Front Blade G and Rear Blade E, "Tandem Wind Rotor GG" is composed of Front and Rear blade $\mathrm{G}$.

The model wind rotors were set perpendicular to the wind direction, at the outlet of the wind tunnel with the nozzle

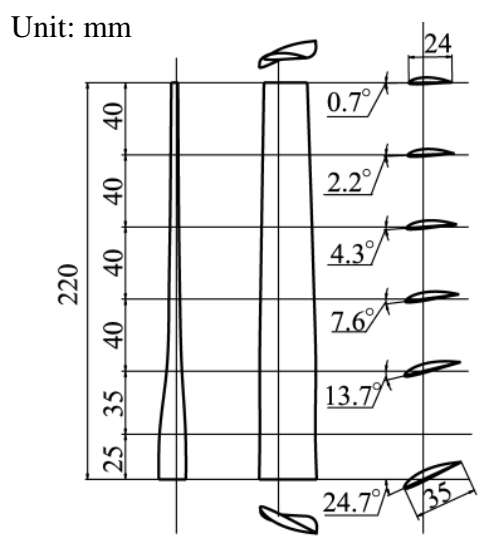

Fig.3 Blade profiles of front blade $\mathrm{G}$ diameter $800 \mathrm{~mm}$, as shown in Fig. 5. The front and the rear wind rotors were connected directly and respectively to the isolated motor with the inverter, in place of the peculiar generator. The rotational torques of both wind rotors were counter balanced by the rotational speed control. The wind rotor performances in the following discussions are evaluated without the mechanical losses caused by the bearings and the pulley system.

\section{Performances of Model Wind Rotors}

The effects of the blade profiles on the wind rotor output are shown in Figs. 6, where $\lambda_{T}$ is the relative tip speed ratio [ $=$ (the relative tip speed) / (the wind velocity)], $C_{P}$ is output coefficient $\left[=P /\left(\rho A V^{3} / 2\right), P\right.$ : the output, $\rho$ : the ambient air density, $A$ : the projection area of the front wind rotor, $V$ : the wind velocity], $L=l / d_{F}, \beta_{F}$ and $\beta_{R}$ are the blade setting angles defined in Fig. 7. The blade

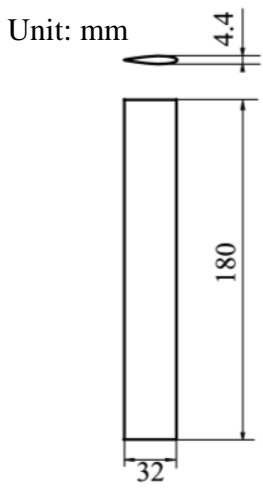

Rear blade $\mathrm{E}$

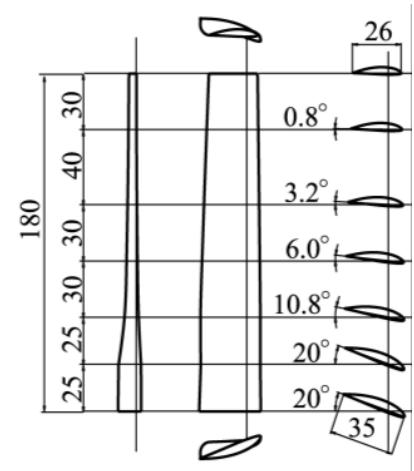

Rear blade $\mathrm{G}$
Fig.4 Blade profiles of Rear Blade E and G

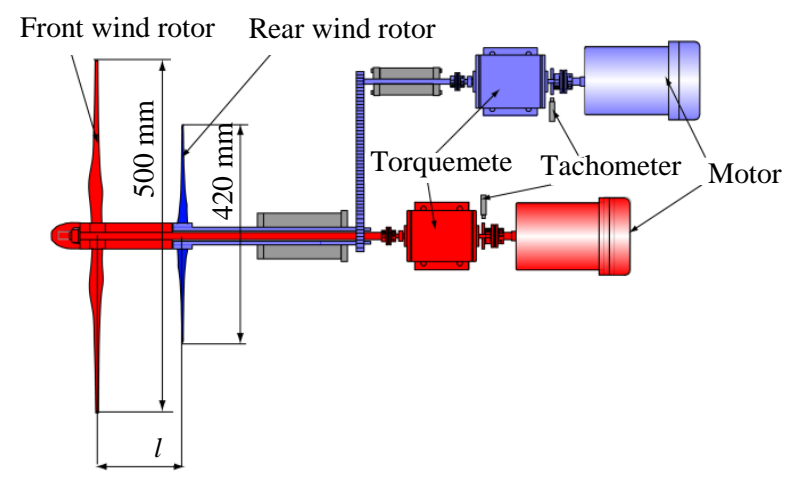

Fig. 5 Test stand for model tandem wind rotors 


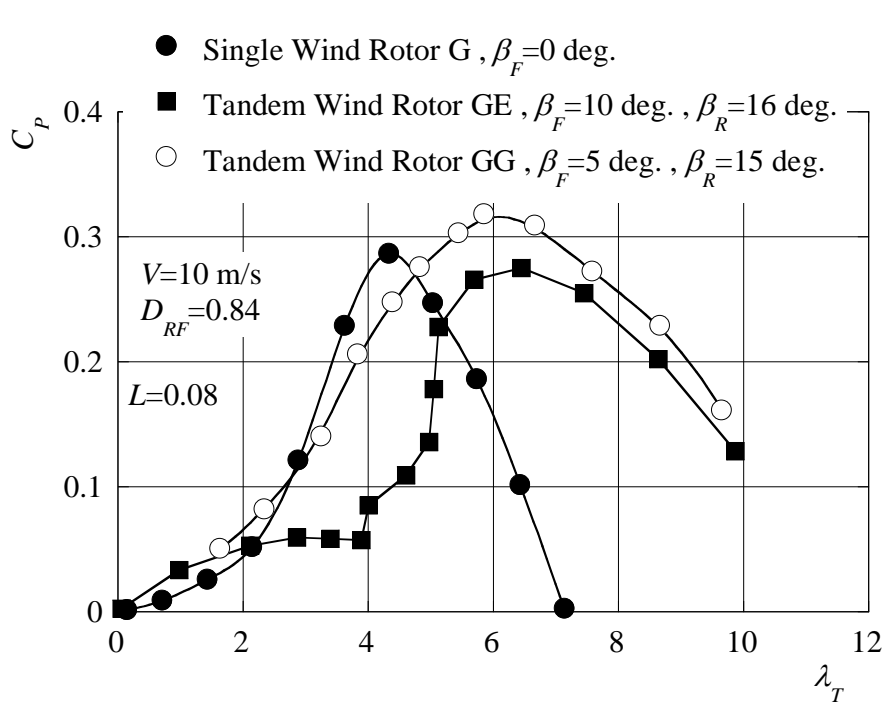

Fig.6 Output characteristics of single wind rotor and tandem wind rotors

setting angles are optimized for each wind rotor profile at the exploratory experiments. The relative tip speed ratio giving the maximum output of Tandem Wind Rotor GG and GE are faster than that of Single Wind Rotor G, but the output of Tandem Wind Rotor GE is unacceptable owing to the twistless rear blade. The twist improves doubtly and successfully the maximum output coefficient, as confiremed by Tandem Wind Rotor GG.

\section{Flow Conditions around Wind Rotors}

The flow around the wind rotors are measured in the steady state conditions, using the 5 holes Pitot tube, where the measurement sections are shown in Fig. 8. Figure 9 shows the flow condition around the single wind rotor with Front Blade $G$ at the maximum output operation, where $R$ is dimensionless radius $\left[=2 r / d_{F}\right.$, $V_{M t m}, V_{\Theta t m}$ and $V_{R t m}$ are the axial, the swirling (positive in the rotational direction of the front wind rotor) and the radial (positive in the outward direction) velocity

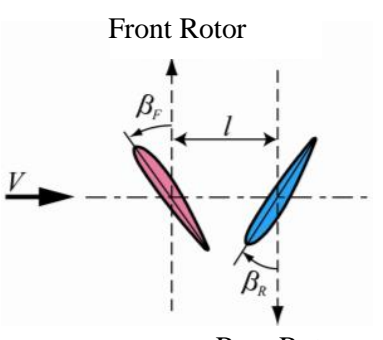

Rear Rotor components averaged in time and divided by the inlet wind velocity $V$ at the datum section $\mathrm{M} 0$, and the angle of attack $\alpha$ is estimated from the flow conditions at M1 and the blade setting angles at each radial positions. The flow runs outwards even at the inlet section M1, due to the Fig.7 Blade setting angles blockage effect of the wind

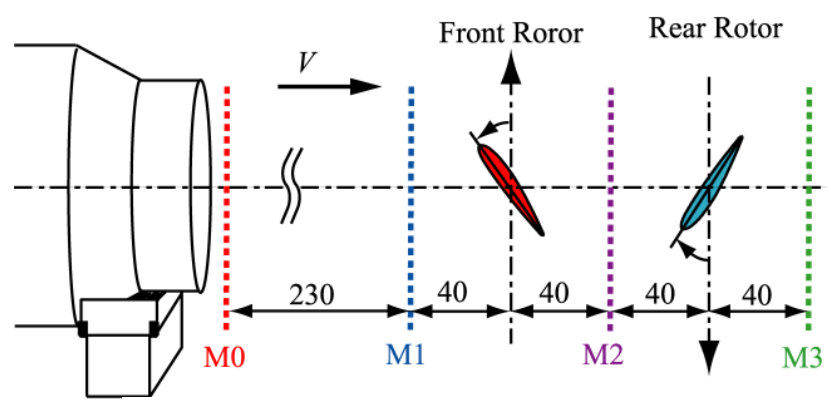

Fig.8 Positions of the measurement sections rotor, and the axial velocity $V_{M t m}$ decreases more or less. The flow runs outward still more while passing through the wind rotor, and $V_{R t m}$ increases obviously near the blade tip at the outlet section M2. Such outward flows contribute to decrease the axial velocity.

The angle of attack $\alpha$ is fairly acceptable because the flow may not have the stall judging from the performance data of MEL002 aerofoil (6), and the rotor works fruitefully with the free vortex type swirling velocity as expected at the blade design.

Figure 10 shows the flow conditions around the Tandem Wind Rotor GG at the maximum output operation. The outward flow velocity is almost the same as that of Single Wind Rotor $\mathrm{G}$ at the small radius, but is somewhat slower at the large radius. The axial velocity
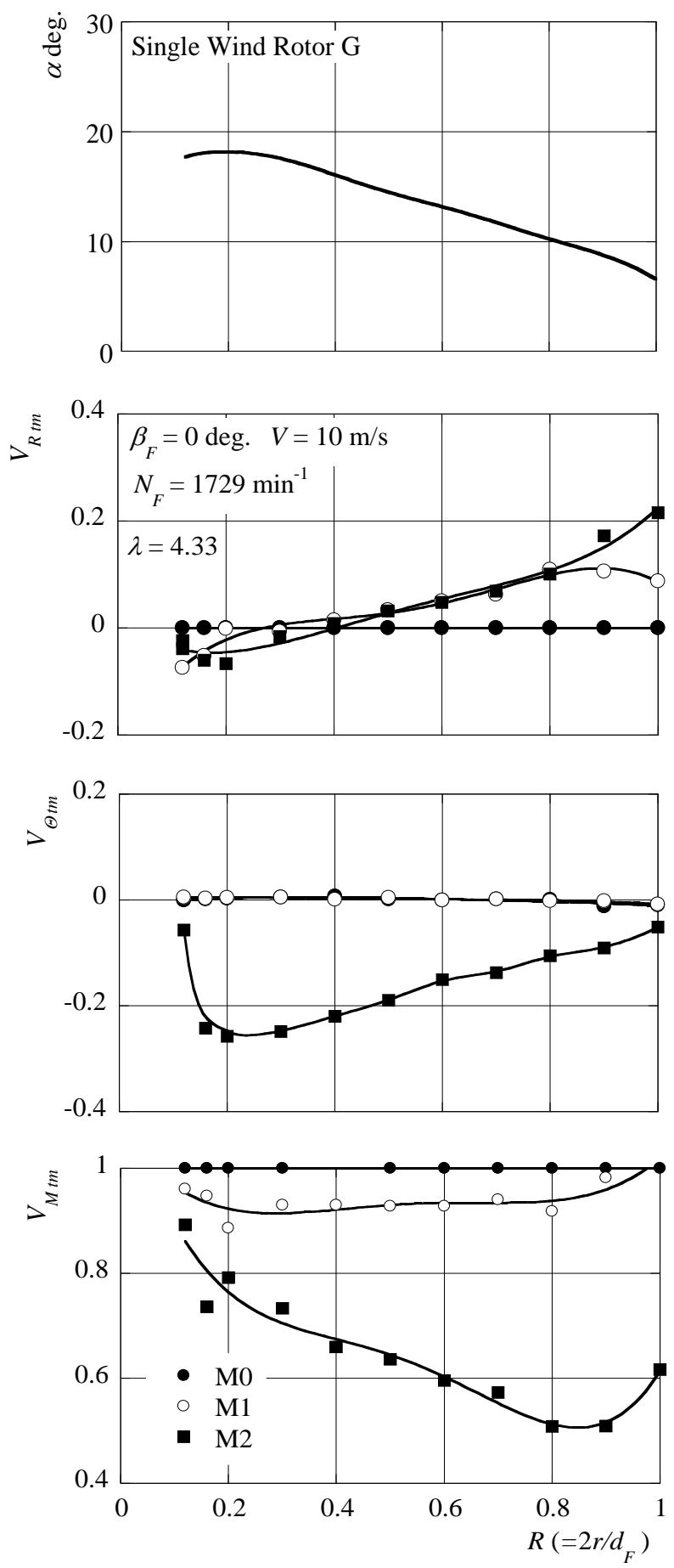

Fig.9 Flow conditions around the Single Wind Rotor G. 
$V_{M t m}$ distribution, however, quite differs from Single Wind Rotor $\mathrm{G}$ with $\beta_{F}=0$ degree, through the absolute value cannot be compared due to the difference of the rotational speed affecting the blaockag. The axial velocity $V_{M t m}$ distribution at the section M2 is controlled by the front wind rotor, namely the blade setting angles. That is, $V_{M t m}$ distribution becomes similar to the distribution in Fig. 9, when the front blade setting angle is changed to $\beta_{F}=0$ degree (see the dash line in Fig. 10).

The angle of attack $\alpha$ to the front blade is slightly larger than that of Single Wind Rotor G (see Fig. 9) at the large radius, but the angle scarcely provokes the large separation on the front blade ${ }^{(6)}$. Besides, angle of attack $\alpha$ to the rear blade, which is estimated by the flow conditions at the section M2, is also reasonable. Then, the output can be improved, though the individual

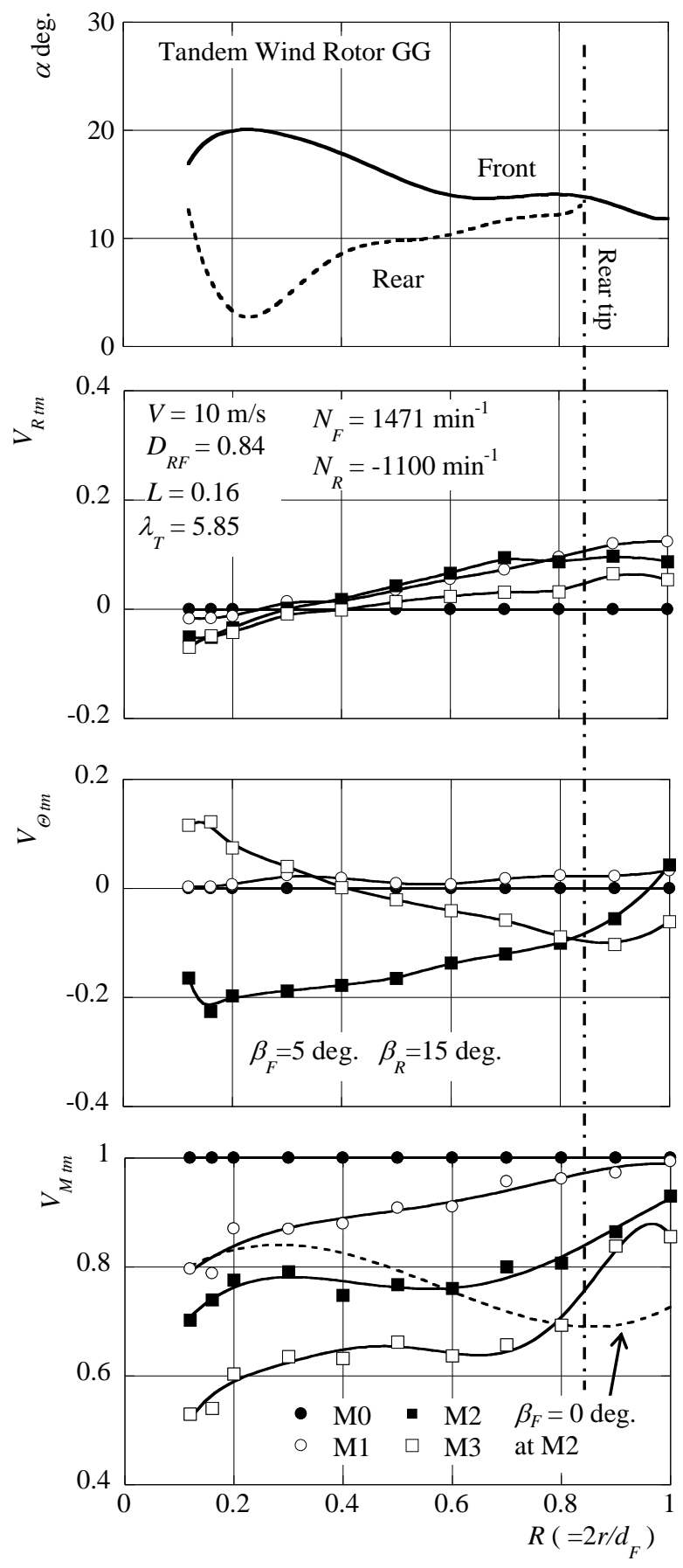

Fig.10 Flow conditions around Tandem Wind Rotor angular momentum change through the front and the rear wind rotors is somewhat small as compared with the moment through the single wind rotor $\mathrm{G}$ (see $V_{\Theta t m}$ in Figs. 9 and 10).

\section{Acoustic Noise}

To know the acoustic noise emitten from the tandem wind rotors, the miniature model of Tandem Wind Rotor GG (downsized to $46 \%$ ) was set in the anechoic box as shown in Fig. 11. The model wind rotors stand downstream of the wind tunnel nozzle, where the axial distance was changed from $L=l / d_{F}=0.08$ to 0.18 . The microphone as the sound-level meter was set on the rotation plane of the front wind rotor, at the distance of $300 \mathrm{~mm}$ from the rotor shaft in the radial direction.

In the experiments, the output signal from the soundlevel meter was accumulated in a FFT analyzer. The noise level and the frequency of the acoustic noise were evaluated without the background noises. The rotational speeds of both wind rotors, namely the tip speed ratios, were adjusted reasonably through the operating conditions in the performance experiments presented above, while the wind velocity was kept constant $V=9$ $\mathrm{m} / \mathrm{s}$ with the Raynolds number $\operatorname{Re}=l_{C} w_{F T} / v=1.3-3.9$ $\mathrm{x} 10^{5}\left(l_{C}\right.$ and $w_{F T}$ : the blade chord and the relative wind velocity at the front blade tip). The intensity of the measured noise differ more or less from the intensity of the prototype with the larger wind rotors, but may give the evaluation data to reduce the noise.

Figure 12 shows the power spectrum density of the acoustic noise, where the relative, the front and the tip speed ratios $\lambda_{T}, \lambda_{F}, \lambda_{R}$ are at the maximum output operation with the front and the rear wind rotor speed $N_{F}$ $=2330 \mathrm{~min}^{-1}$ and $N_{R}=-1844 \mathrm{~min}^{-1}$. The blade passing frequencies are $N_{F} Z_{F}=117 \mathrm{~Hz}$ at the front wind rotor and $N_{R} Z_{R}=154 \mathrm{~Hz}$ at the rear wind rotor, and $L_{A e q, T}=64.1$ $\mathrm{dB}$ gives the equivalent continuous $\mathrm{A}$-weighted sound pressure level. These frequencies are hardly observed, but there are many dominant frequencies which may be attributed to the flow interaction between the front and the rear wind rotors. Hanson has predicted the dominant frequency in the counter-rotating propellers ${ }^{(7)}$. That is, the dominant frequency $f$ due to the flow interaction can be obtained from $f=\left|m Z_{F} N_{F}+k Z_{R} N_{R}\right|$, where $m$ and $k$ are the integral integer number $(-\infty \sim \infty)$ giving the harmonic frequency of $Z_{F} N_{F}$ and $Z_{R} N_{R}$. Table 1 shows the

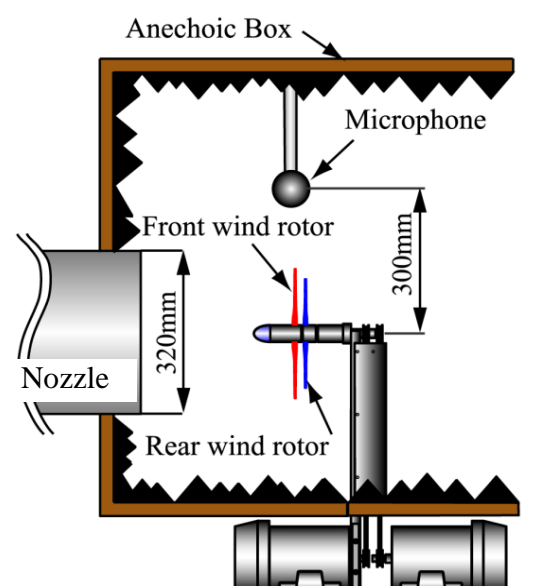

Fig.11 Model wind turbine for the acoustic noise experiments 
dominant frequencies derived from above equation, at the maximum output operation specicied above. These values coincide well with the experimental results shown in Fig. 12.

Figure 13 shows the effect of the axial distance $L=l /$ $d_{F}$ on the sound pressure level $L_{\text {Aeq, } T}$ at $\lambda_{T}=5.58$. The level $L_{\text {Aeq, } T}$ at $L=0.08$ is $3.3 \mathrm{~dB}$ higher than that at $L=$ 0.18 . Figure 14 shows the power spectrum density at $L=$ 0.08 and 0.18. Some dominant frequencies appear obviously at $L=0.08$ where the rear wind rotor is in close to the front wind rotor. These results are paradox that the noise is acceptable but the output is not acceptable at longer distance $L$ or the output is acceptable but the noise is not acceptable at shorter distance $L$, where the output is high with the decreas of the distance $L^{(5)}$. That is, it may be nessesary, for Intelligent Wind Power Unit constracted at onshores, to reduce the acoustic noise for getting the higher output.

\section{Concluding Remarks}

The output, the flow conditions and the acoustic noise of the model tandem wind rotors were investigated experimentally. The reasonable tandem wind rotors make the output higher with the increase of the tip speed ratio, as compared with the traditional wind turbines composed of the single wind rotor. The acoustic noise is induced mainly from the flow interaction between the front and the rear wind rotors, and has the dominant

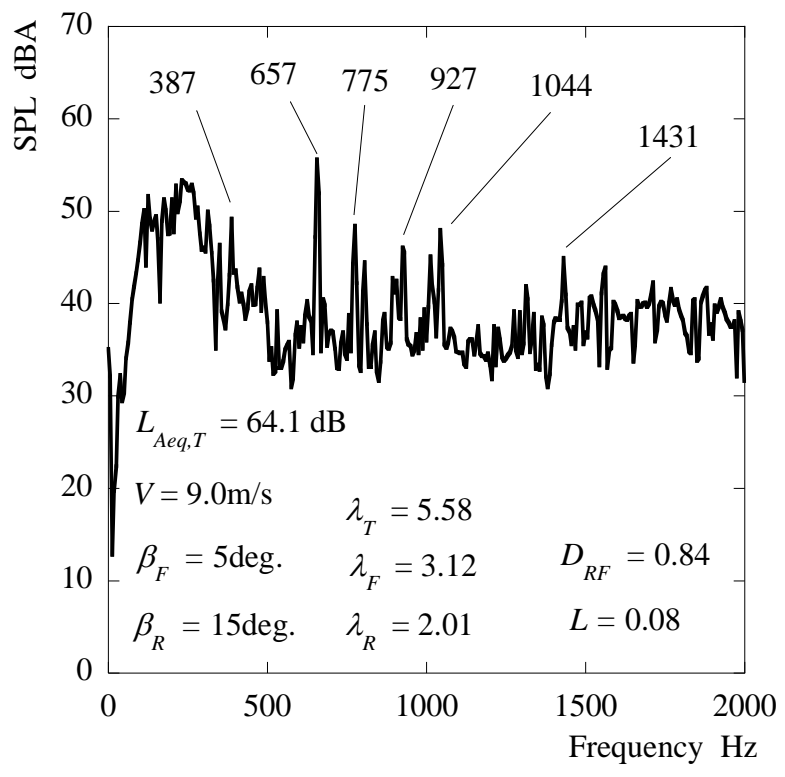

Fig.12 The power spectrum density at $\lambda_{T}=5.58$

Table 1 Predicted frequencies derived from $\mid m Z_{R} N_{R}+k Z_{F} N_{F}$ $\lambda_{T}=5.58$ with $N_{R}=1844 \mathrm{~min}^{-1}, Z_{R}=5, N_{F}=2330 \mathrm{~min}^{-1}, Z_{F}=3$

\begin{tabular}{|c|c|c|}
\hline $\begin{array}{c}\text { Sound harmonic } \\
m\end{array}$ & $\begin{array}{c}\text { Load harmonic } \\
k\end{array}$ & $\begin{array}{c}\text { Frequency } \\
f \text { Hz }\end{array}$ \\
\hline 1 & 2 & 387 \\
\hline \multirow{2}{*}{2} & 3 & 657 \\
\cline { 2 - 3 } & 4 & 773 \\
\hline \multirow{2}{*}{3} & 4 & 927 \\
\cline { 2 - 3 } & 5 & 1044 \\
\hline 4 & 7 & 1430 \\
\hline
\end{tabular}

power spectrum density at the harmonic frequencies of the blade passing.

\section{Acknowledgement}

The authors wish to thank Messrs. Nobuhiko Mihara and Yohei Hano, Akira Enishi and Sho Nonoue graduated from Kyushu Institute of Technology, Mr. Tatsuro Nunoya and Miss Sachi Inai of Kyushu Institute of Technology for helpful in doing experiments and discussed about this paper. Some parts of this fundamental research were co-sponsored by JFE 21st Century Foundation, Research Project: Grant-in-aid for Scientific Research (c) (2) 1997-2010, Research project: Grant-in-aid for JSPS fellow and The Iwatani Naoji Foundation 2009, in Japan

\section{References}

1. Kanemoto, T., and Ahmed Mohamed Galal., 2006, "Development of Intelligent Wind Turbine Generator with Tandem Wind Rotors and Double Rotational Armatures," JSME International Journal, Ser. B, Vol. 49, No. 2, pp.450-457.

2. Ushiyama, I. et al., 1996, "An Experimental Study of the Two Staged Wind Turbines," Proceedings of World Renewable Energy Conference, pp. 909-912.

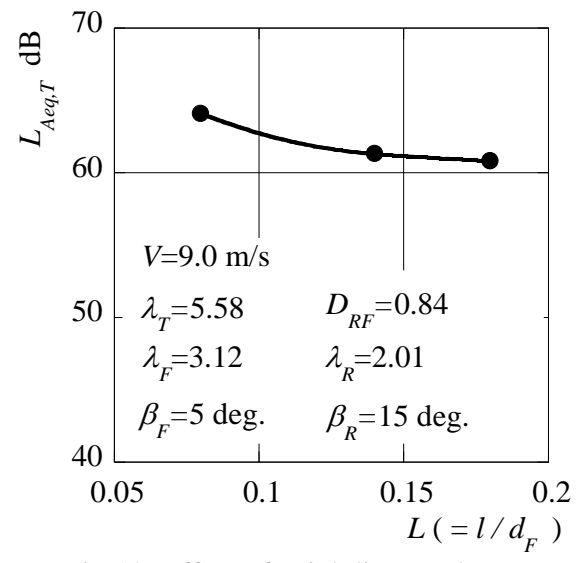

Fig.13 Effect of axial distance between both wind rotors on the $L_{\text {Aeq, }}$

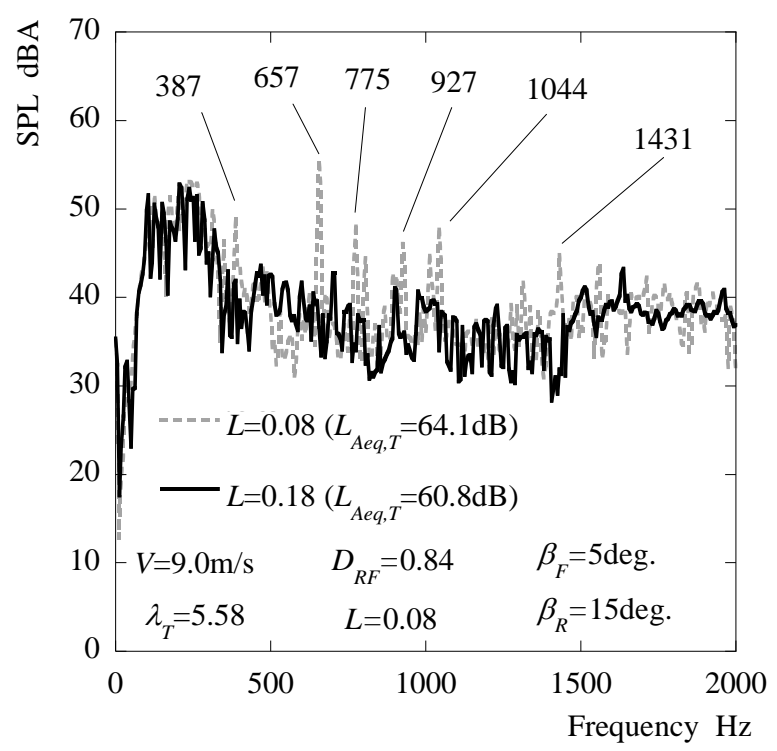

Fig.14 The power spectrum density at $L=0.08$ and $L=0.18$ 
3. Jung, S.N. et al., 2005, "Aerodynamic Performance prediction of $30 \mathrm{~kW}$ counter-rotating wind turbine system," Renewable Energy, Vol. 30, No. 5, pp. 631-644.

4. Kanemoto, T. et al., 2007, "Intelligent Wind Turbine Generator with Tandem Rotors Applicable to Offshore Wind Farm (Characteristics of Peculiar Generator, and Performance of Three Dimensional Blades)", Proceedings of the 17th International Offshore and Polar Engineering Conference, Lisbon, Portugal, pp.363-368.

5. Kubo, K., and Kanemoto, T., 2008, "Development of Intelligent Wind Turbine Unite with Tandem Wind Rotors and Double Rotational Armatures (2nd report, characteristics of tandem wind rotors)," JSME International Journal of fluid science and technology, Vol.3, No.3, pp.370-378.

6. Performance and geometry of airfoils supply system, online, http://riodb.ibase.aist.jp/db060/index.html

7. Hanson, D.B., 1985, "Noise of Counter-rotation Propellers," J.Aircraft, 22, p.609. 